\title{
Surgical revascularization of critical ischemia of lower limbs: current guidelines and personal experience
}

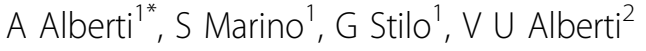 \\ From de Senectute: Age and Health Forum \\ Catanzaro, Italy. 5-7 December 2009
}

\section{Background}

Peripheral arterial occlusive disease (PAOD) of lower extremities has been attributed primarily to atherosclerotic changes and the risk factor associated with atherosclerotic disease, including smoking, male gender, hypercholesterolemia, diabetes and age. The prevalence of CLI in general population as an adjusted rate of 3-5\%.

Critical limb ischemia is the most debilitating symptom of PAOD. The rational treatment of the CLI is surgery or endovascular approach.

The present study was performed to determine the outcome of infrainguinal by-pass a popliteo-to-distal by-pass surgery for limb salvage in the treatment of the critical limb ischemia.

Result of lower extremity by-pass surgery have traditionally been assessed by patency rate, uncomplicated wound healing, limb salvage, and patient survival rate.

\section{Materials and methods}

Limb salvage patients included in this study from December 2004 to January 2009. Limb salvage indication for surgery were defined as ischemic rest pain, ischemic ulcer or gangrene, acute or subacute ischemia and ankle-brachial index pressure less than 0,5.

The patients treated with surgery revascularization for CLI were 96. In this group, the infrainguinal bypass was performed on 62 , and the popliteo-tibial bypass was performed on 34 .

Operative results, including mortality and morbility data, primary patency rate, healing of ischemic wounds, limb salvage rate, and patients survival rate . Primary patency and patient survival rate calculated in the 6-month, 3-year and 5-year by life table methods.

\section{Results}

During a 4 year period of study we recorded : Mortaliy in this group study six-patients (7\%), cumulative morbility 36 patients $(38 \%)$; mean primary patency $82 \%$ and mean limb salvage (88\%); healing ischemic wounds.

The present study was undertaken evaluate to evaluate the validity of the infrainguinal and popliteo-to-distal bypass in the treatment of critical limb ischemia.

The traditionally of placing the anastomosis of infrainguinal by-pass in the common femoral artery prevailed until 1981, when the short bypass principle was proposed, popliteal-to-distal-by-pass has evolved as the most typical short bypass which is applicable to only a small fraction of patients who have nearly popliteal artery pulse and obstructive pathology of the pedal artery.

With the use PTA for the treatment of the short lesions in the superficial femoral artery, there has been an increase in the applicability of a PD bypass. A major advantage of this PD bypass is the possibility of frequently using of the GSV in situ or reversed configuration.

\section{Conclusions}

The infrainguinal bypass and popliteal-to-distal bypass (in the obstructive pathology of the pedal vessel) is a tool of high efficiency in the treatment of severe, chronic critical ischemia in the lower limb. 


\section{Author details}

'Department of Surgery, Operative Unit of Vascular and Endovascular

Surgery, Riuniti Hospital City of Reggio Calabria, 89124, Italy. ${ }^{2}$ Department of Cardiovascular Surgery, Operative Unit of Vascular Surgery, "San Filippo Neri" Hospital, City of Rome, 00135, Italy.

Published: 19 May 2010

doi:10.1186/1471-2318-10-S1-A40

Cite this article as: Alberti et al: Surgical revascularization of critical ischemia of lower limbs: current guidelines and personal experience.

BMC Geriatrics 2010 10(Suppl 1):A40.

Submit your next manuscript to BioMed Central and take full advantage of:

- Convenient online submission

- Thorough peer review

- No space constraints or color figure charges

- Immediate publication on acceptance

- Inclusion in PubMed, CAS, Scopus and Google Scholar

- Research which is freely available for redistribution

Submit your manuscript at www.biomedcentral.com/submit 